\title{
Toxicity of blue led light and A2E is associated to mitochondrial dynamics impairment in ARPE-19 cells: implications for age-related macular degeneration
}

\author{
Agustina Alaimo ${ }^{1}$. Guadalupe García Liñares ${ }^{2}$ Juan Marco Bujjamer ${ }^{3} \cdot$ Roxana Mayra Gorojod ${ }^{1}$. \\ Soledad Porte Alcon ${ }^{1} \cdot$ Jimena Hebe Martínez ${ }^{1}$. Alicia Baldessari ${ }^{2} \cdot$ Hernán Edgardo Grecco $^{3} \cdot$ Mónica Lidia Kotler $^{1}(\mathbb{0}$
}

Received: 10 December 2018 / Accepted: 6 February 2019

(c) Springer-Verlag GmbH Germany, part of Springer Nature 2019

\begin{abstract}
Age-related macular degeneration (AMD) is a multifactorial retinal disease characterized by a progressive loss of central vision. Retinal pigment epithelium (RPE) degeneration is a critical event in AMD. It has been associated to A2E accumulation, which sensitizes RPE to blue light photodamage. Mitochondrial quality control mechanisms have evolved to ensure mitochondrial integrity and preserve cellular homeostasis. Particularly, mitochondrial dynamics involve the regulation of mitochondrial fission and fusion to preserve a healthy mitochondrial network. The present study aims to clarify the cellular and molecular mechanisms underlying photodamage-induced RPE cell death with particular focus on the involvement of defective mitochondrial dynamics. Light-emitting diodes irradiation $\left(445 \pm 18 \mathrm{~nm} ; 4.43 \mathrm{~mW} / \mathrm{cm}^{2}\right)$ significantly reduced the viability of both unloaded and A2E-loaded human ARPE-19 cells and increased reactive oxygen species production. A2E along with blue light, triggered apoptosis measured by MC540/PI-flow cytometry and activated caspase-3. Blue light induced mitochondrial fusion/fission imbalance towards mitochondrial fragmentation in both non-loaded and A2E-loaded cells which correlated with the deregulation of mitochondria-shaping proteins level (OPA1, DRP1 and OMA1). To our knowledge, this is the first work reporting that photodamage causes mitochondrial dynamics deregulation in RPE cells. This process could possibly contribute to AMD pathology. Our findings suggest that the regulation of mitochondrial dynamics may be a valuable strategy for treating retinal degeneration diseases, such as AMD.
\end{abstract}

Keywords Age-related macular degeneration $\cdot$ RPE cells $\cdot$ Aging $\cdot$ Light pollution $\cdot$ Phototoxicity $\cdot$ A2E $\cdot$ Oxidative stress $\cdot$ Mitochondrial dynamics

\section{Introduction}

Age-related macular degeneration (AMD) is a late-onset and progressive neurodegenerative disease which primarily damages the central region of the retina (macula) (Wong et al. 2014). AMD affects people over 50 years of age generating a remarkable negative impact on the physical and mental health. AMD is likely to increase becoming a major financial and public health burden. Unfortunately, limited beneficial treatment for AMD is available and prevention may be the

Guadalupe García Liñares and Juan Marco Bujjamer contributed equally to this work.

Mónica Lidia Kotler

kotler@qb.fcen.uba.ar; moniquekotler@gmail.com

Extended author information available on the last page of the article first approach to reduce the vision loss (Berman and Brodaty 2006; Kaarniranta et al. 2013; Fernandez-Robredo et al. 2014; Blasiak et al. 2017).

AMD is a complex multifactorial disease. The risk factors include age, genetics, smoking, gender, nutrition, hypertension, obesity and sunlight exposure (Arnault et al. 2013; Sui et al. 2013; Fritsche et al. 2014; Lambert et al. 2016). The influence of light exposure has been extensively discussed and nowadays it is accepted as an important factor in AMD progression (Jaadane et al. 2017).

Light pollution, particularly the blue light emitted by light-emitting diodes (LED) bulbs has increased with the advent of new technologies. LEDs have emerged as an important source of light replacing the conventional lamps (fluorescent lamps, incandescent bulb, Edison socket, etc.). They are considered a next generation of lighting sources due to their inherent and potential advantages over other 
technologies such as low energy consumption and long life. Nowadays, LEDs are included in screens of computers, tablets, smartphones and televisions, as well as used to provide illumination in industrial and commercial environments. Particularly, white LEDs are essentially a bichromatic source that couples the emission from a blue LED light with yellow phosphor (Kuse et al. 2014; Tosini et al. 2016). It has been recognized that blue light could potentially produce retinal toxicity leading to the development of degenerative eye diseases, such as AMD (Contín et al. 2013; Kuse et al. 2014; Jaadane et al. 2015, 2017).

The retinal pigment epithelium (RPE) is a monolayer of pigmented cells that exerts several physiological roles critical for retinal homeostasis. It is relevant for the bloodretinal barrier formation, nutrients and waste products transport, phagocytosis of photoreceptor's outer segments, synthesis and release of growth factors and the isomerization of all-trans-retinal into 11-cis-retinal during the visual cycle (Jaadane et al. 2017; Ao et al. 2018). In AMD, the RPE progressively degenerates, resulting in photoreceptor death and visual loss. Many studies have recognized oxidative stress and photodamage as contributing factors for RPE dysfunction. $N$-Retinylidene- $N$-retinylethanolamine (A2E), a known fluorophore of lipofuscin, contributes at least in part, to RPE cells degeneration. A2E acts as a self-oxidant that sensitizes RPE cells to photochemical damage mediated by blue light exposure (Wihlmark et al. 1997; Sparrow et al. 2003; Brandstetter et al. 2015; Marie et al. 2018).

Mitochondrial dysfunction represents a crucial hallmark of aging and age-related pathologies (Lionaki et al. 2015). Rigorous systems of mitochondrial quality control have evolved to maintain mitochondrial homeostasis and avoid cell death. A line of defence against injury is provided by the dynamic nature of this organelle. Mitochondria continuously undergo fission and fusion events. Fission allows the recycling of damaged components via the segregation of injured organelles while fusion enables the exchange of material with healthy mitochondria (Suen et al. 2008; McBride and Scorrano 2013; Kotiadis et al. 2014; Stotland and Gottlieb 2015). There is growing evidence supporting an association between mitochondrial dysfunction and a number of retinal pathologies including AMD. Particularly, impaired mitochondrial function and mitochondrial DNA damage have been reported in AMD (Godley et al. 2005; Karunadharma et al. 2010; Barot et al. 2011).

The present work clarifies the cellular and molecular mechanisms underlying phototoxicity in human retinal pigment epithelium ARPE-19 cells under short illumination periods and demonstrates for the first time that mitochondrial dynamics plays a role in blue LED light-induced damage in A2E-loaded cells.

\section{Materials and methods}

\section{Reagents and antibodies}

Dulbecco's Modified Eagle's Medium/Ham's F12 (DMEM/F12) was from Gibco, (Thermo Fisher Scientific, Inc., MA, USA); trypsin, 3-(4,5-dimethyl-thiazol2-yl)-2,5-diphenyl-tetrazolium bromide (MTT), Hoechst 33258 fluorochrome, Merocyanine 540, 2', 7'-dichlorodihydrofluorescein diacetate (DCDHF-DA), rotenone and ECL detection reagents (luminol and $p$-coumaric acid) were purchased from Sigma-Aldrich Co. (St. Louis, MO, USA). Fetal bovine serum (FBS) was obtained from Natocor (Córdoba, Argentina). Streptomycin, penicillin and amphotericin B were from Richet (Buenos Aires, Argentina). Lysotracker Red DND-99 and MitoSOX Red were from Molecular Probes (Eugene, OR, USA). Alltrans-retinal (CAS 116-31-4) was purchased from Santa Cruz Biotechnology Inc. (Santa Cruz, CA, USA). The following antibodies were employed: caspase-3 (H-277): sc-7148 (1:500), DRP1 (H-300): sc-32898 (1:500), OMA1 (H-11): sc-515788 (1:200), $\beta$-Actin (C4): sc-47778 (1:1000), mouse IgG-HRP: sc-2031 (1:1000), rabbit IgGHRP: sc-2030 (1:1000) (Santa Cruz Biotechnology Inc.); anti-cleaved caspase-3 (Asp175): \#9661 (1:100) (Cell Signaling Technology, Danvers, MA, USA); anti-OPA1: \#612607 (1:1000) (BD Pharmingen, San Diego, CA, USA); Alexa fluor 488 goat anti-Rabbit $\operatorname{IgG}(\mathrm{H}+\mathrm{L})$ : \# A-11008 (1:1000), Alexa Fluor 555 Goat Anti-Rabbit IgG $(\mathrm{H}+\mathrm{L})$ : \# A27039 (Molecular Probes, Eugene, OR, USA).

Final concentration of dimethyl sulfoxide (DMSO) did not exceed $0.25 \%$. DMSO added to the samples did not affect neither cell viability, morphology nor others parameters tested in this study. All others chemicals used were of the highest purity commercially available.

\section{Cell line and growth conditions}

ARPE-19 (ATCC ${ }^{\circledR}$ CRL-2302 ${ }^{\mathrm{TM}}$ ) cell line which is devoid of endogenous A2E (Sparrow and Cai 2001) was kindly provided by Dr. Angela Suburo and Dr. Mariela Marazita (Facultad de Ciencias Biomédicas, Universidad Austral, Pilar, Buenos Aires, Argentina). ARPE-19 is a spontaneously arising human RPE cell line that maintains normal karyology as well as structural and functional properties of RPE cells in vivo (Dunn et al. 1996). Cells were cultured in DMEM/F12 supplemented with $10 \%$ heat-inactivated FBS, $2.0 \mathrm{mM}$ glutamine, 100 units $/ \mathrm{mL}$ penicillin, $100 \mu \mathrm{g} /$ $\mathrm{mL}$ streptomycin and $0.25 \mu \mathrm{g} / \mathrm{mL}$ amphotericin $\mathrm{B}$ at $37^{\circ} \mathrm{C}$ in a humidified atmosphere of $5 \% \mathrm{CO}_{2}-95 \%$ air. Medium was renewed three times a week. For all experiments, 
ARPE-19 cells were detached with $0.05 \%$ trypsin-EDTA, diluted with DMEM 10\% FBS and re-plated into multiwell plates to yield $70-80 \%$ confluent cultures after $24 \mathrm{~h}$. Then, cells were washed with phosphate buffered saline (PBS) and used for exposure studies.

\section{Blue LED illumination}

A LED-based device was designed with a $5 \times 4$ blue LEDs $(1 \mathrm{~W})$ array, a maximum irradiance wavelength of $445 \mathrm{~nm}$, a half bandwidth of $18 \mathrm{~nm}$ and an output power of $4.43 \mathrm{~mW} /$ $\mathrm{cm}^{2}$. A diffuser material was employed to achieve optimal homogeneity of the output illumination. Thus, a maximum deviation of $0.6 \mathrm{~mW} / \mathrm{cm}^{2}$ was reached among the wells. Furthermore, the radiant heat output was measured to confirm that temperature mediated effects were negligible. Cells growing in multi-well plates were exposed to blue LED light for different times (1-60 min) in a humidified atmosphere of $5 \% \mathrm{CO}_{2}$ at $37{ }^{\circ} \mathrm{C}$ and incubated for additional $24 \mathrm{~h}$ in the dark. Unexposed cells were used as controls.

\section{A2E synthesis and loading}

A2E was synthesized according to Parish et al. (1998) with slight modifications. In brief, all-trans-retinal $(50 \mathrm{mg}$, $175 \mu \mathrm{mol})$ was mixing with ethanolamine $(70 \mu \mathrm{L}, 75 \mu \mathrm{mol})$ in dichloromethane $(3 \mathrm{~mL})$ containing acetic acid $(5 \mu \mathrm{L})$ and stirred in the dark at room temperature (RT) for 3 days. The solvent was evaporated to dryness. The residue was purified by silica gel column chromatography using $\mathrm{CH}_{3} \mathrm{OH}: \mathrm{CH}_{2} \mathrm{Cl}_{2}$ (5:95) and $\mathrm{CH}_{3} \mathrm{OH}: \mathrm{CH}_{2} \mathrm{Cl}_{2}$ :TFA (8:92:0.001), obtaining A2E $(23.8 \mathrm{mg}, 51 \%)$ with $9 \%$ of iso-A2E (estimated by ${ }^{1} \mathrm{H}-\mathrm{NMR}$ ). For ARPE-19 cells exposure experiments, A2E was delivered in culture media for $24 \mathrm{~h}$. All assays included unloaded cells as control.

\section{Cell viability assays}

\section{MTT reduction}

The conversion of MTT to formazan by mitochondrial dehydrogenases was used as an index of cell viability according to the protocol previously described by Mosmann (1983) with slight modifications (Alaimo et al. 2011). After exposure, cells grown on 96-well plates were washed with PBS and incubated with MTT $(0.5 \mathrm{mg} / \mathrm{mL})$ in culture media for $60 \mathrm{~min}$ at $37^{\circ} \mathrm{C}$. Then, formazan was solubilized in $200 \mu \mathrm{l}$ of DMSO. Absorbance was measured at $570 \mathrm{~nm}$ with background subtraction at $655 \mathrm{~nm}$ in a BIO-RAD Model 680 Benchmark microplate reader (BIO-RAD laboratories, Hercules, CA, USA). The MTT reduction activity was expressed as a percentage of control cells.

\section{Neutral Red retention}

Neutral Red (NR) assay was carried out to evaluate cell viability following the protocol described by Gorojod et al. (2015). After exposure, cells grown on 96-well plates were washed with PBS and $200 \mu \mathrm{L}$ of NR solution in culture media were added to each well $(40 \mu \mathrm{g} / \mathrm{mL}$, previously warmed at $37{ }^{\circ} \mathrm{C}$ overnight (ON) and centrifuged $10 \mathrm{~min}$ at $2600 \mathrm{RPM})$. After incubation $\left(2 \mathrm{~h}, 37^{\circ} \mathrm{C}\right)$, cells were washed once with PBS and $200 \mu \mathrm{L}$ of acid alcohol solution $(1 \% \mathrm{v} / \mathrm{v}$ acetic acid in $50 \%$ ethanol) were added to each well until complete dye dissolution. Absorbance was measured at $570 \mathrm{~nm}$ with background subtraction at $690 \mathrm{~nm}$ in a BIORAD Model 680 Benchmark microplate reader. Results were expressed as a percentage of the corresponding control cells.

\section{Reactive oxygen species (ROS) measurement}

\section{Total ROS levels}

This assay was carried out according to the protocol described by Gorojod et al. (2018). Intracellular ROS generation was measured by the oxidation of the reagent $2^{\prime}$, 7'-DCFH-DA to the fluorescent compound 2', 7'-dichlorofluorescein (DCF). After treatments, cells were loaded with $15 \mu \mathrm{M}$ DCFH-DA and incubated for $30 \mathrm{~min}$ at $37^{\circ} \mathrm{C}$. Next, medium was removed, placed into a black 96 well plate and fluorescence was recorded. The resulting cells were incubated with hypotonic solution $(\mathrm{KCl} 7.5 \mathrm{mM}, \mathrm{pH} 7)$ for $1 \mathrm{~h}$ at $37^{\circ} \mathrm{C}$. Lysate was homogenized and centrifuged at $12,800 \times g 15 \mathrm{~min}$. The supernatant was placed into a black well plate and fluorescence was recorded. The obtained data, corresponding to the sum of the measurements, was relativized to total protein amount determined by Bradford assay (Bradford 1976). As positive control for ROS production, cells were incubated with $250 \mu \mathrm{M}$ hydrogen peroxide for $24 \mathrm{~h}$. Fluorescence was measured at $\lambda_{\mathrm{ex}}=480 \mathrm{~nm}$ and $\lambda_{\mathrm{em}}=530 \mathrm{~nm}$ using FLUOstar OPTIMA microplate (BMG LABTECH, Ortenberg, Germany).

\section{Mitochondrial ROS levels}

MitoSOX Red, a cationic derivative of dihydroethidium (DHE), is a fluorogenic dye employed for selective detection of mitochondrial $\mathrm{O}_{2}{ }^{-}$in live cells. MitoSOX Red is live-cell permeant and is rapidly and selectively targeted to the mitochondria where it reacts with $\mathrm{O}_{2}{ }^{-}$to produce 2-hydroxymitoethidium, which excites and emits at 510 and $580 \mathrm{~nm}$, respectively. Despite its proposed specificity, it has been demonstrated that MitoSOX Red can also undergo unspecific reactions with other oxidants to form mito-ethidium, which overlaps the 2-hydroxymitoethidium fluorescence peak $(510 \mathrm{~nm})$. Then, it has been proposed another 
specific excitation peak at $400 \mathrm{~nm}$ for 2-hydroxymitoethidium (Robinson et al. 2008; Wojtala et al. 2014). Therefore, two different excitation wavelengths are used to distinguish the $\mathrm{O}_{2}{ }^{--}$as we previously described (Gorojod et al. 2018). After treatments, cells were loaded with MitoSox Red $5 \mu \mathrm{M}$ for $10 \mathrm{~min}$ at $37^{\circ} \mathrm{C}$ in the dark. Fluorescence intensity of the cell lysates was measured in a FLUOstar OPTIMA fluorometer $\left(\lambda_{\mathrm{ex}}: 510 \mathrm{~nm}\right.$ or $\left.400 \mathrm{~nm} ; \lambda_{\mathrm{em}}: 590 \mathrm{~nm}\right)$. Values were normalized to the total amount of proteins determined by Bradford assay. As positive control for $\mathrm{O}_{2}{ }^{-}$production, cells were incubated with $300 \mu \mathrm{M}$ rotenone for $10 \mathrm{~min}$.

In a separate set of experiments cells grown on coverslips were treated and then incubated with $5 \mu \mathrm{M}$ MitoSOX Red for $10 \mathrm{~min}$ at $37{ }^{\circ} \mathrm{C}$ in the dark. Afterwards, cells were washed twice with PBS and mounted on glass slides. Samples were examined under a fluorescence microscope Olympus IX71 equipped with objective lens $60 \times / 1.43$ oil $\left(\lambda_{\text {ex }}\right.$ : $543 / 20 \mathrm{~nm} ; \lambda_{\mathrm{em}}: 593 / 40 \mathrm{~nm}$ ). Images were captured with a Hamamatsu Photonics ORCA-ER camera. Digital images were optimized for contrast and brightness using Adobe Photoshop 7.0 Software, Tokyo.

\section{Apoptosis assay}

Apoptotic cells were identified according to the protocol described by Laakko et al. (2002) validated in our laboratory Porte Alcon et al. (2018). Flow cytometric analysis employing Merocyanine 540 (MC540) and propidium iodide (PI) was performed. Briefly, treated cells were harvested by trypsinization, centrifuged and washed twice with PBS. MC540 stock solution ( $1 \mathrm{mg} / \mathrm{mL}$ ) was prepared in 50\% ethanol and diluted with harvest buffer (HBBS containing $10 \mathrm{mM}$ HEPES and 4\% heat-inactivated FBS). Cells were stained with $100 \mu \mathrm{L}$ MC540 $(7.5 \mu \mathrm{M})$ for $10 \mathrm{~min}$ at RT and protected from light. Before analysis, $900 \mu \mathrm{L}$ harvest buffer was added to each sample and stained with $10 \mu \mathrm{L}$ PI $(1 \mu \mathrm{g} /$ $\mathrm{mL}) . \operatorname{MC5} 40\left(\lambda_{\mathrm{ex}}: 488 \mathrm{~nm}, \lambda_{\mathrm{em}}: 575 \pm 26 \mathrm{~nm} ; \mathrm{FL}-2\right)$ and PI $\left(\lambda_{\mathrm{ex}}: 488 \mathrm{~nm}, \lambda_{\mathrm{em}}: 660 \pm 17 \mathrm{~nm}\right.$; FL-3) fluorescence emission was measured in FACS Aria II flow cytometer (BD Biosciences, San Jose, CA, USA), with proper compensation between channels. All gating and analysis were done on at least 10,000 cells per sample. Cells were classified in three categories: live ( $\mathrm{PI}^{-} \mathrm{MC} 540^{-}$), early apoptotic $\left(\mathrm{PI}^{-} \mathrm{MC} 540^{+}\right)$and late apoptotic/necrotic $\left(\mathrm{PI}^{+} \mathrm{MC} 540^{+}\right)$. Data were analyzed employing FlowJo 7.6 (TreeStar, Ashland, USA).

\section{Western blotting}

Western blots were performed according to the procedure well described by Alaimo et al. (2014). Briefly, ARPE-19 cells were suspended in lysis buffer (50 mM HEPES/0.1\% Triton X-100 pH 7.0, 0.5 mM PMSF, $10 \mu \mathrm{g} / \mathrm{mL}$ aprotinin and $10 \mu \mathrm{g} / \mathrm{mL}$ benzamidine) and incubated for $30 \mathrm{~min}$ at $4{ }^{\circ} \mathrm{C}$. After centrifugation $\left(10,000 \times g, 20 \mathrm{~min}, 4^{\circ} \mathrm{C}\right)$, protein concentration was determined using Bradford assay (Bradford 1976). Equal amount of protein $(70-100 \mu \mathrm{g})$ from each treatment was separated on 10-12\% SDS-polyacrylamide gel electrophoresis (SDS PAGE) and blotted onto nitrocellulose membranes (Hybond ECL, GE Healthcare, Piscataway, NJ, USA). Transference efficiency was verified by staining the membrane with Ponceau Red. Non-specific binding sites were blocked by $5 \%$ non-fat dried milk in TBS $(150 \mathrm{mM}$ $\mathrm{NaCl}$ in $50 \mathrm{mM}$ Tris- $\mathrm{HCl}$ buffer $\mathrm{pH} 8$ ) containing $0.1 \%$ SDS, for $90 \mathrm{~min}$. Then membranes were incubated with specific antibodies $\mathrm{ON}$ at $4{ }^{\circ} \mathrm{C}$. The primary antibody reaction was followed by incubation for $1 \mathrm{~h}$ with horseradish peroxidase-conjugated secondary antibodies. All antibodies were diluted in TBST $(150 \mathrm{mM} \mathrm{NaCl}, 0.05 \%$ Tween 20 , in $10 \mathrm{mM}$ Tris- $\mathrm{HCl}$ buffer $\mathrm{pH} 8$ ) with $3 \%$ non-fat dried milk. Immunoreactive bands were detected employing enhanced chemiluminescence western blotting detection reagents (ECL). Images were captured with Amersham ${ }^{\mathrm{TM}}$ Imager 600 and imaging software (GE Healthcare Life Sciences, Chalfont, UK). Quantitative changes in protein levels were evaluated employing ImageJ software.

\section{Immunocytochemistry}

Immunocytochemical analyses were assessed as previously described (Alaimo et al. 2013). Fixed samples with 4\% paraformaldehyde/4\% sucrose (4\% PFA-S) were permeabilized with $0.25 \%$ Triton X-100 in PBST $(0.1 \%$ Tween 20 in PBS $\mathrm{pH}$ 7.4) for $10 \mathrm{~min}$ at RT. Then, cells were washed three times with PBS for 5 min and non-specific binding sites were blocked with $1 \%$ BSA in PBST ON at $4{ }^{\circ} \mathrm{C}$. Coverslips were incubated with primary antibodies ( $1 \mathrm{~h}, \mathrm{RT}$ ) (antiTOM-20 or anti-cleaved caspase-3), washed three times with PBS and then incubated with secondary antibodies $(1 \mathrm{~h}, \mathrm{RT})$ (Alexa fluor 488 or 555 goat anti-rabbit IgG, respectively) in the dark.

Then cells were washed twice with PBS, stained with Hoechst $33258(1 \mu \mathrm{g} / \mathrm{mL})$, washed again with PBS and examined under a confocal microscope Olympus FV300 (Olympus Optical Co., Tokyo, Japan) equipped with the image acquisition software Fluoview 5.0 (Olympus Optical Co.) employing an Olympus $60 \times$ oil-immersion Plan Apo objective.

\section{Live-cell acidic vesicles marker and fluorescence microscopy}

For acidic vesicles detection, A2E-loaded cells grown on coverslips were washed twice with PBS and incubated with Lysotracker Red DND-99 (100 nM) in serum-free media for $30 \mathrm{~min}$ at $37^{\circ} \mathrm{C}$. Then, cells were washed twice with PBS, 
fixed with 4\% PFA-S in PBS 30 min at RT and washed five times with PBS. Samples were examined under a confocal microscope Olympus FV300 fluorescence microscope.

\section{Statistical analysis}

Experiments were carried out in triplicate unless otherwise stated. Results are expressed as mean \pm standard error of the mean (SEM) values. Experimental comparisons between treatments were made by Student's $t$ test or one-way ANOVA, followed by Student-Newman-Keuls post hoc test with statistical significance set at $p<0.05$. All analyses were carried out with GraphPad Prism 5 software (San Diego, CA, USA).

\section{Results}

\section{Blue LED light exposure induces time-dependent cytotoxicity in ARPE-19 cells}

The wavelengths of blue light are among the highest energy of the visible light spectrum. Particularly, the spectral range between 415 and $455 \mathrm{~nm}$ is the most harmful of the blue light (380-500 nm) for primary porcine RPE cells (Arnault et al. 2013). In the present work, a $445 \mathrm{~nm}$ blue LED-based illumination device was especially designed to apply a unified energy $\left(4.43 \mathrm{~mW} / \mathrm{cm}^{2}\right)$ to cell cultures grown in multiwell plates (Fig. 1a). This irradiance was chosen to mimic physiological light conditions reaching the retina according to Arnault et al. (2013). Device's radiant heat output was controlled to exclude any thermic effect. The spectral wavelength profile of the blue light source used in this study is shown in Fig. 1b.

To investigate the possible cytotoxic effects of blue light, human ARPE-19 cells were irradiated for different times (1-30 min) and cell viability was analyzed after $24 \mathrm{~h}$ by both MTT and NR assays. As shown in Fig. 1c exposure to blue light resulted in a time-dependent reduction in cell viability. Particularly, after $30 \mathrm{~min}$ of irradiation, a $48 \pm 5 \%(p<0.001)$ and a $38 \pm 2 \%(p<0.01)$ decrease was determined by MTT and NR, respectively. Moreover, we observed a reduction in cell monolayer confluence as well as cell detachment by employing phase-contrast microscopy, supporting the occurrence of cell death (Fig. 1d).

\section{Blue LED light irradiation induces ROS generation}

Retinal pigment epithelium cells are especially sensitive toward oxidative stress due to their high metabolic activity, substantial oxygen consumption, elevated content of polyunsaturated fatty acids and constant exposure to sunlight and/ or electronic devices (Winkler et al. 1999; Kaarniranta et al. 2013; Kauppinen et al. 2016).

To evaluate whether blue LED light induces mitochondrial ROS generation, ARPE-19 cells were irradiated for 1-60 min, loaded with MitoSOX Red and fluorescence intensity quantified by spectrofluorometry. Mitochondrial ROS production peaked after $1 \mathrm{~min}$ light exposure $\left(\lambda_{\mathrm{ex}}=510 \mathrm{~nm}\right.$ : $74 \%$ and $\left.\lambda_{\text {ex }}=400 \mathrm{~nm}: 80 \%, p<0.01\right)$. Remarkably, results obtained at both 400 and $510 \mathrm{~nm}$ excitation were similar, indicating that $\mathrm{O}_{2}{ }^{-}$was specifically detected (Fig. 2a). Mitochondrial $\mathrm{O}_{2}{ }^{--}$generation was confirmed by fluorescence microscopy (Fig. 2c). Interestingly, augmented fluorescence was associated with mitochondrial morphological changes. Irradiation with blue light induced mitochondrial fragmentation as a function of time. Considering that the increase in $\mathrm{O}_{2}{ }^{-}$generation declined over time $\left(30 \mathrm{~min}: \lambda_{\mathrm{ex}}=510 \mathrm{~nm}\right.$ : $31 \%$ and $\lambda_{\text {ex }}=400 \mathrm{~nm}: 23 \%, p<0.01,60 \mathrm{~min}$ : no statistically different vs. controls), we next measured total intracellular ROS levels using the oxidation-sensitive probe DCHF-DA. A time-dependent increment in ROS generation after blue light irradiation was detected (1 $\mathrm{min}: 35 \%, p<0.05 ; 30 \mathrm{~min}$ : $82 \% ; p<0.01)$ (Fig. 2b).

\section{Blue LED light exposure induces apoptosis and promotes mitochondrial fragmentation}

Apoptosis activation has been reported in many retinal degeneration models. However, in the last years, controversial results have emerged regarding to the type of cell death and the role of caspase- 3 in different models of light-induced retina degeneration (Contín et al. 2013; Huang et al. 2014; Torriglia et al. 2016). Therefore, experiments were designed to clarify the role of caspase-3 in blue LED light-induced cell death in our model.

ARPE-19 cells were exposed to blue light for different times (1-30 $\mathrm{min}$ ) and caspase-3 expression levels were analyzed after $24 \mathrm{~h}$. Western blot showed increased procaspase-3 levels after $1 \mathrm{~min}$ irradiation $(62 \pm 11 \% ; p<0.01)$ (Fig. 3a). To further investigate the occurrence of apoptotic cell death induced by blue irradiation, a flow cytometry analysis employing MC540 and PI double labeling was performed (Fig. 3b). Our results demonstrate that $30 \mathrm{~min}$ blue light exposure induces a 2.3-fold increment in the early apoptotic cells (Q3) $(p<0.05)$. Considering that late apoptotic/necrotic population (Q2) is also increased (2.3-fold vs. control) and this methodology does not discern between necrotic and apoptotic events in Q2, other types of cell death should not be discarded.

Mitochondrial dynamics play important roles in the mitochondrial quality control. While increased fusion favors the mixing of mitochondrial components, and thus the complementation and dilution of damaged mitochondria, mitochondrial fission allows the clearance of dysfunctional 
A

LED-based blue light setup source
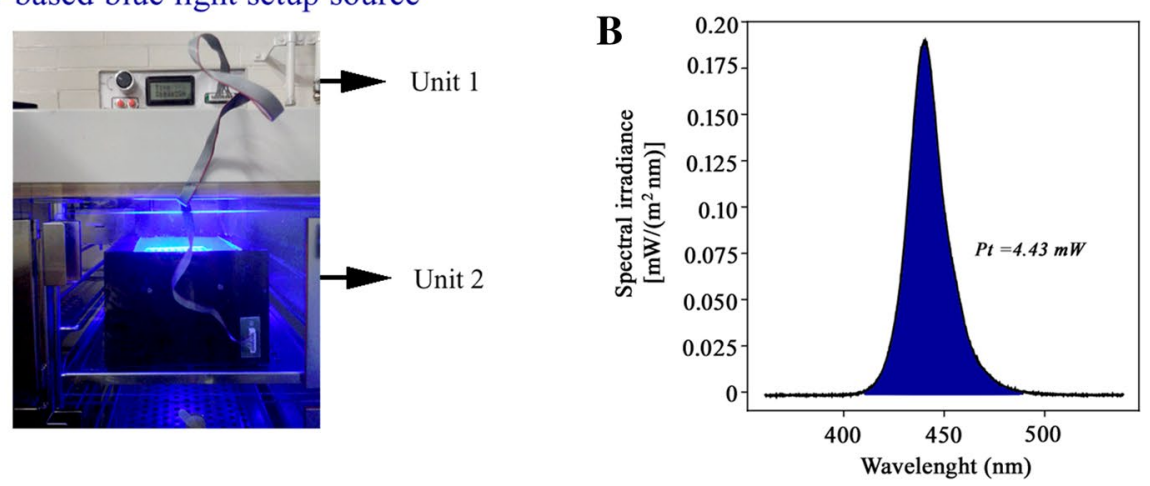

C
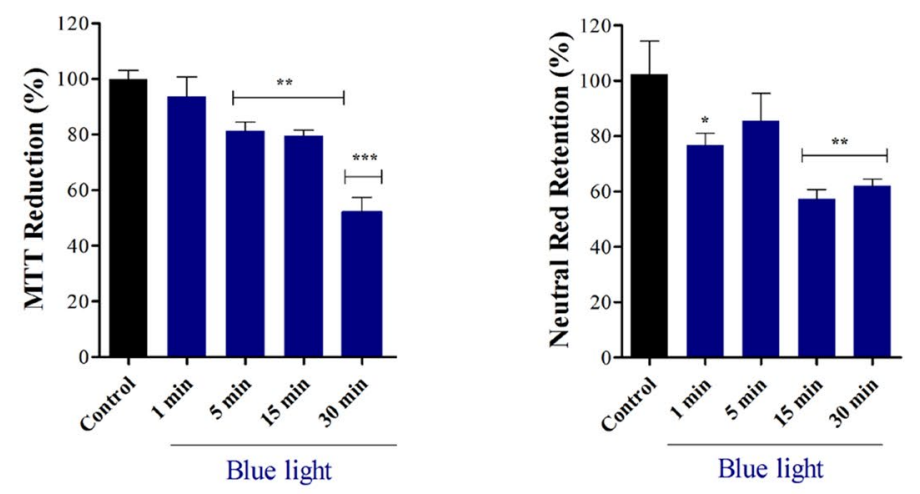

Blue light $\left(4.43 \mathrm{~mW} / \mathrm{cm}^{2}\right)$

D
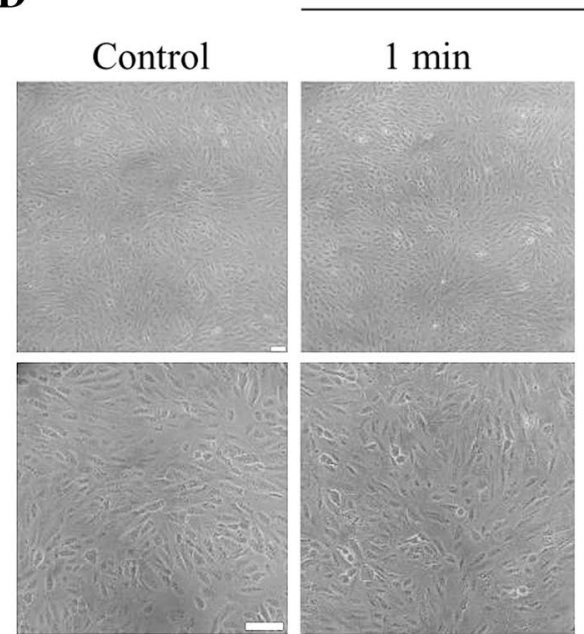

$5 \mathrm{~min}$
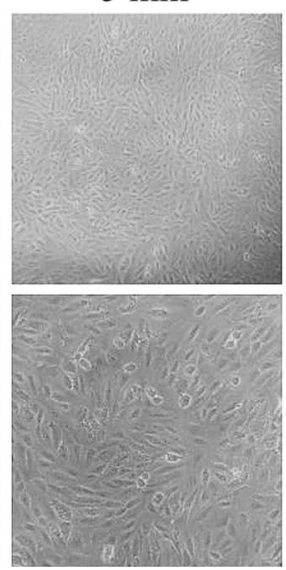

$15 \mathrm{~min}$
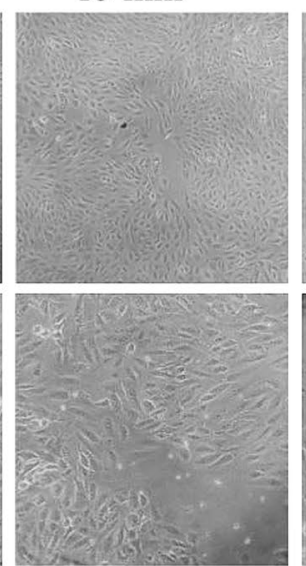

$30 \mathrm{~min}$
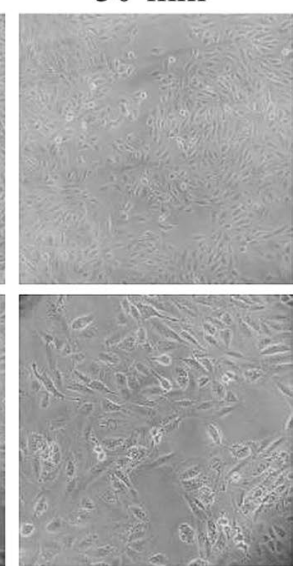

Fig. 1 Blue LED light exposure-induced cytotoxicity in ARPE19 cells. a LED-based blue light setup source. Unit 1 is the output power device and Unit 2, designed to be located in the cell incubator, provides a uniform illumination to the cells. b Blue LED light spectral wavelength profile. c Cells were cultured in the dark (control) or exposed to blue light for 1-30 min and cell viability was assessed by

mitochondria through mitophagy. On the other hand, massive mitochondrial fission is induced upon severe stress and constitutes an early step in apoptosis induction (Youle and
MTT or Neutral Red assays. Data were expressed as average \pm SEM. Statistically significant differences between the controls and experimental groups are indicated by: $* p<0.05, * * p<0.01, * * * p<0.001$ vs. control. d Representative images of phase-contrast microscopy showing the morphological changes induced by blue light exposure in ARPE-19 cells. Scale bar: $50 \mu \mathrm{m}$

Karbowski 2005; Liesa et al. 2009; McBride and Scorrano 2013). Immunocytochemical analysis of TOM-20 (a central component of TOM, translocase of the outer membrane 

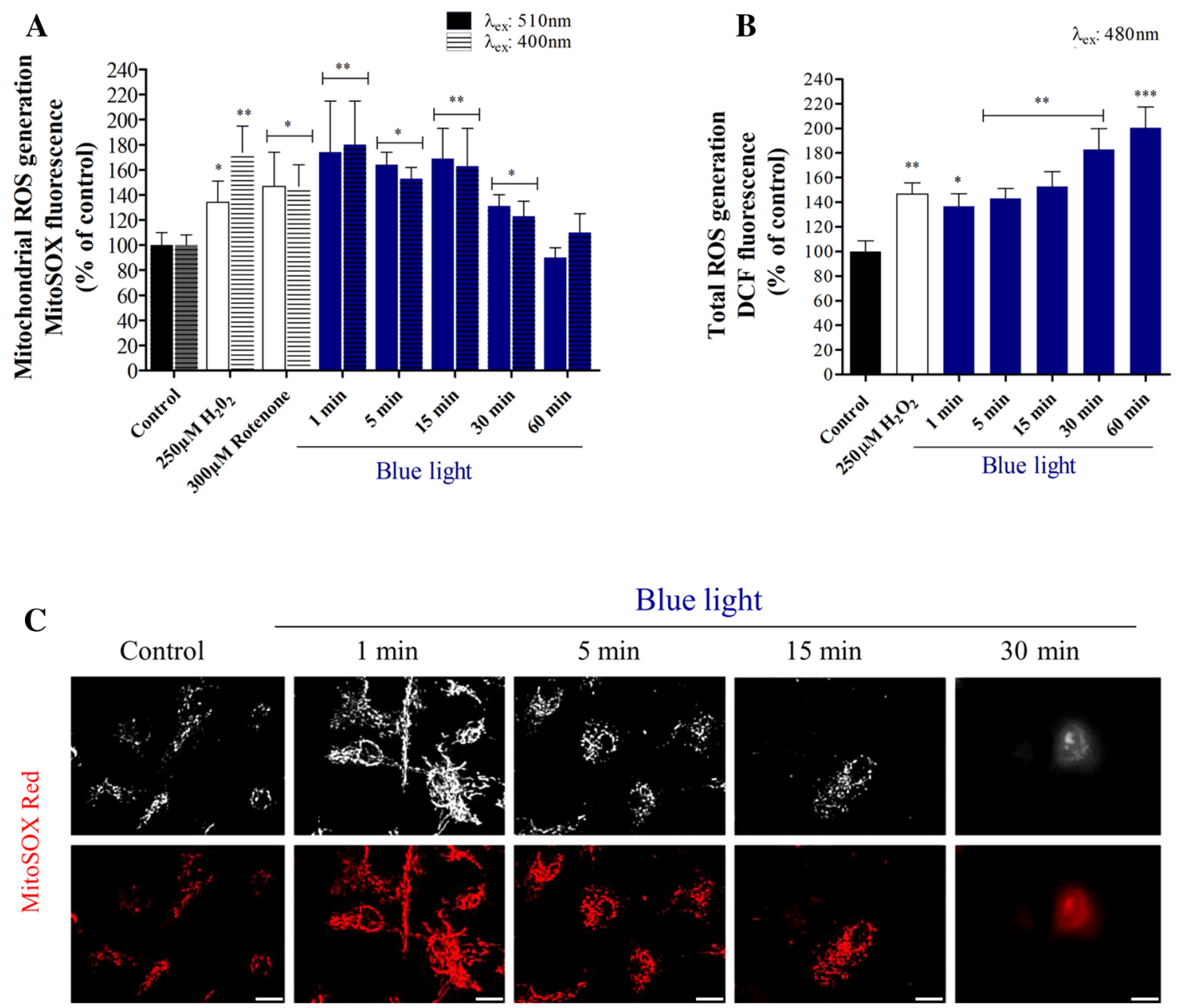

Fig. 2 Blue LED light irradiation induces ROS generation. Mitochondrial (a) and total intracellular ROS (b) generation were measured by spectrofluorometry. Control and irradiated (1-60 min) cells were loaded with $5 \mu \mathrm{M}$ MitoSOX Red ( $\lambda_{\mathrm{ex}}: 400$ or $\left.510 \mathrm{~nm}, \lambda_{\mathrm{em}}: 590 \mathrm{~nm}\right)$ or $15 \mu \mathrm{M}$ DCFH-DA $\left(\lambda_{\mathrm{ex}}=480 \mathrm{~nm}, \lambda_{\mathrm{em}}=530 \mathrm{~nm}\right)$. Hydrogen perox-

receptor complex) was performed to analyze mitochondrial morphology (Fig. 3c). Control cells displayed tubular, filamentous-like mitochondria while blue light-irradiated cells exhibited a significant increase in multiple punctiform fragmented mitochondria supporting the occurrence of observations described in Fig. 2c.

To deepen in the mechanisms responsible for blue lightinduced mitochondrial fragmentation, we investigated the effects of light exposure on the expression of the mitochondrial shaping proteins. DRP1 (Dynamin-related protein 1) is considered the master regulator of fission while OPA1 (Optic atrophy protein 1) is crucial for mitochondrial membranes fusion and the maintenance of the proper mitochondrial cristae architecture (McBride and Scorrano 2013). In accordance with the observed increase in mitochondrial fission (Fig. 3c), western blot analysis revealed both decreased OPA1 and increased DRP1 expression levels after ide and rotenone were used as positive controls. Data are expressed as mean \pm SEM. $* p<0.05$, **p $p<0.01$, *** $p<0.001$ vs. control (ANOVA, Newman-Keuls post-hoc test). c Control and irradiated ARPE-19 cells were stained with $5 \mu \mathrm{M}$ MitoSox Red and visualized by fluorescence microscopy. Scale bar: $10 \mu \mathrm{m}$

5 min irradiation. Particularly, 30 min of blue light exposure decreased $40 \%$ the expression levels of OPA1 $(p<0.001)$ whereas DRP1 levels were markedly increased $(240 \%$, $p<0.001$ ) (Fig. 3d).

Altogether, these findings demonstrate that LED-derived blue light induced an imbalance in mitochondrial dynamics in ARPE-19 cells.

\section{A2E-induced cell death in ARPE-19 cells involves an apoptotic pathway}

A2E accumulation in RPE cells is a hallmark of AMD (Sparrow et al. 2003; Wolf 2003). To obtain information about the role of A2E in our model, we first incubated ARPE-19 cells with $1-100 \mu \mathrm{M}$ A2E for $24 \mathrm{~h}$ and cell viability was measured by MTT assay. A2E induced a dose-dependent cytotoxicity (10 $\mu \mathrm{M}: 13 \pm 2 \%, p<0.05 ; 25 \mu \mathrm{M}: 29 \pm 4 \%, 50 \mu \mathrm{M}: 64 \pm 4 \%$, 
A

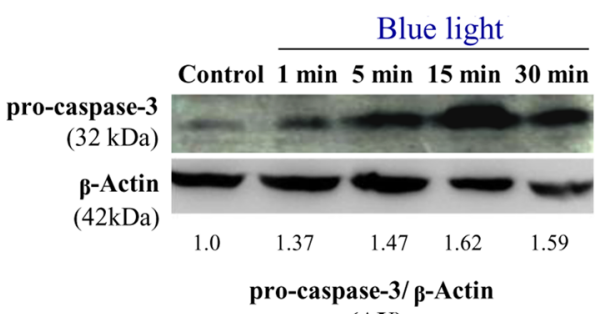

(AU)
B

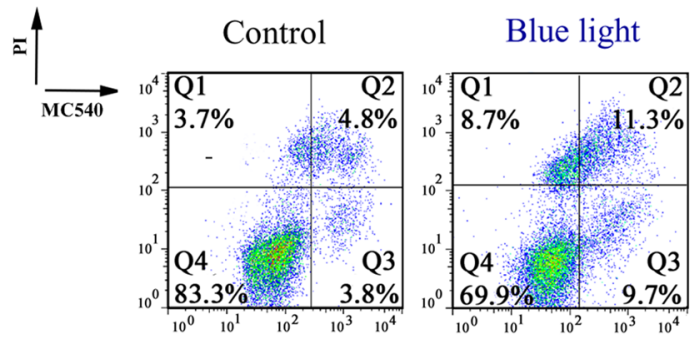

$\square$ Early Apoptotic (A+, PI-) - Late Apoptotic/Necrotic (A+,PI+)

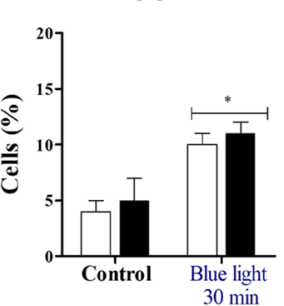

C
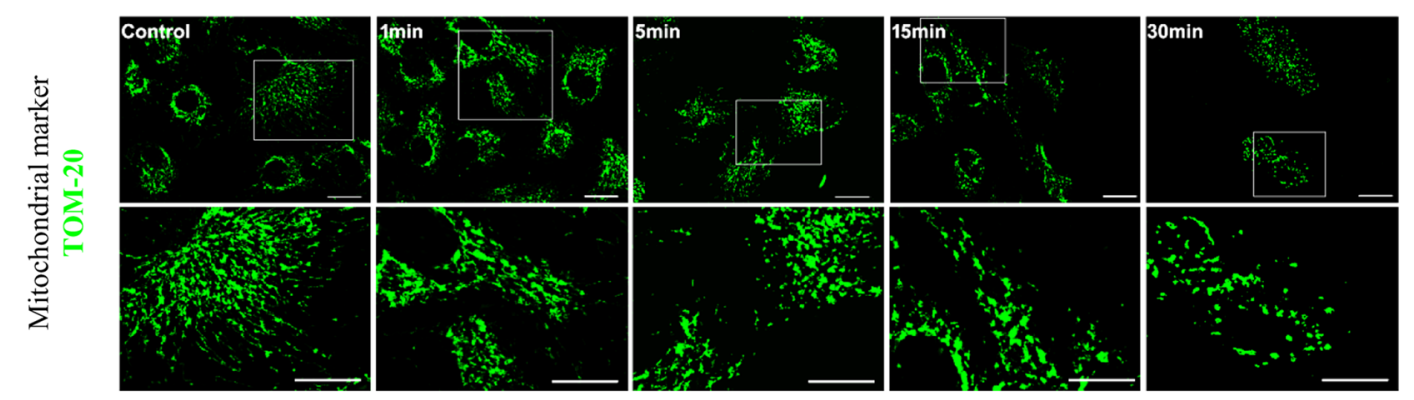

D

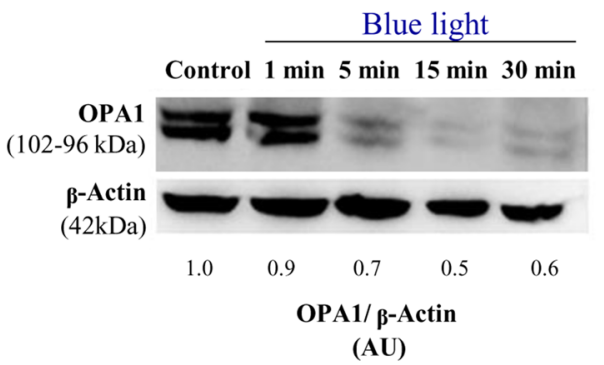

Fig. 3 LED-derived blue light induces apoptosis and mitochondrial dynamics deregulation. a Pro-caspase-3 expression levels were quantified and normalized to $\beta$-Actin. b Left: apoptosis was analyzed with MC450/PI staining. Cells were classified in three categories: live ( $\mathrm{PI}^{-}$ $\left.\mathrm{MC} 540^{-}\right)$, early apoptotic $\left(\mathrm{PI}^{-} \mathrm{MC} 540^{+}\right)$and late apoptotic/necrotic $\left(\mathrm{PI}^{+} \mathrm{MC} 540^{+}\right)$. Right: bar graph quantifying the percentage of cells in early apoptotic, and late apoptotic/necrotic cells. c Epifluorescence images of mitochondria immunolabeled with TOM-20 protein

$100 \mu \mathrm{M}: 80 \pm 2 \%, p<0.001$ ) (Fig. $4 \mathrm{a}$ ). In this experiment, A2E uptake by ARPE-19 cells was disclosed by the presence of a perinuclear pattern of brownish granules (data not shown). Based in cytotoxicity results, we employed 10 and $25 \mu \mathrm{M}$ A2E for future experiments. To confirm the reported preferential accumulation of $\mathrm{A} 2 \mathrm{E}$ in acidic vesicles (AVOs) (Finnemann et al. 2002) the latter were labeled with Lysotracker Red DND-99 and A2E location was tracked by its fluorescent properties (Fig. 4b). Colocalization of A2E and Lysotracker Red signals demonstrated that A2E at least partially accumulates in AVOs.

Next, our purpose was to determine the effect of blue light on cellular integrity in A2E-loaded cells. Cells were exposed to blue light for $30 \mathrm{~min}$ and examined under phase

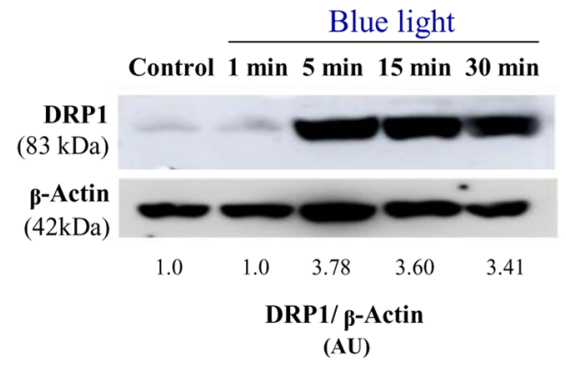

(Alexa Fluor 488, Olympus IX71). Control ARPE-19 cells exhibited normal tubular mitochondrial morphology whereas those exposed to blue light showed increased mitochondrial fragmentation in a timedependent manner. Scale bar: $10 \mu \mathrm{m}$. d Western blot of OPA1 and DRP1 expression levels $(* * * p<0.001$ vs. control). Re-probing with an anti- $\beta$-actin antibody was performed to normalize for protein loading. $A U$ arbitrary units

contrast microscope after $24 \mathrm{~h}$ incubation in the darkness (Fig. 4c). A2E per se induced a decrease in cell monolayer confluence (asterisks) as well as cellular rounding (arrows), resembling the effect previously observed for blue light irradiation (Fig. 1d). When combined (cells loaded with A2E plus irradiation), cell monolayer damage was more pronounced, especially for $25 \mu \mathrm{M}$ A2E. Assessment by MTT assay (Fig. 4d) showed that exposure to blue light increased A2E cytotoxicity to $55 \pm 4 \%$ and $70 \pm 2 \%(p<0.001)$ for 10 and $25 \mu \mathrm{M}$, respectively. Results obtained by MC540/ PI double staining demonstrated that while A2E per se increases both the early apoptotic (Q3) and the late apoptotic/necrotic (Q2) population (Fig. 4e), the additional action of light exacerbates these effects. Furthermore, data from 
Fig. 4e suggest that both conditions A2E and A2E + blue light exposure trigger apoptotic cell death. In support of this observation, immunocytochemical studies employing an anti-active caspase- 3 antibody demonstrated the activation of this caspase in $25 \mu \mathrm{M}$ A2E loaded cells under blue light exposure (Fig. 4f). However, considering that late apoptotic and necrotic cells cannot be resolved by flow cytometry, the contribution of a necrotic pathway should not be neglected.

\section{Mitochondrial dynamics deregulation in A2E-loaded ARPE-19 cells exposed to blue LED light}

Previous reports have established that A2E accumulation in RPE cells at levels comparable to those occurring during aging, decreases mitochondrial oxidative phosphorylation, ATP levels and membrane potential and induces ROS generation and cytochrome c release (Suter et al. 2000; Vives-Bauza et al. 2008; Marie et al. 2018). Furthermore, it has been demonstrated that blue light irradiation contributes with $\mathrm{A} 2 \mathrm{E}$ to the occurrence of some of these processes (Suter et al. 2000; Marie et al. 2018). However, as far as we know, there are no reports describing the combined effect of A2E plus blue light irradiation on mitochondrial dynamics in RPE cells. Thus, to investigate the participation of mitochondrial events triggered by A2E plus light irradiation, we first measured mitochondrial $\mathrm{O}_{2}{ }^{-}$levels employing the MitoSOX Red probe (Fig. 5a). Although 10 and $25 \mu \mathrm{M}$ A2E increase the $\mathrm{O}_{2}{ }^{-}$levels in both non-irradiated and irradiated cells, light exposure did not contribute synergistically with A2E to $\mathrm{O}_{2}{ }^{--}$generation.

Cellular stress may alter mitochondrial behaviour mostly by changing mitochondrial fusion and fission dynamics (Chauhan et al. 2014). Then, to analyze possible disturbances in these processes we quantified mitochondrial morphologies. Cells were classified as exhibiting tubular (normal, filamentous), hyperfused (elongated filamentous), intermediate (filamentous with fragmented regions) and fragmented (cells with globular organelle) mitochondria (Fig. 5b). Interestingly, $10 \mu \mathrm{M}$ A2E led to an increase in the percentage of cells exhibiting hyperfused mitochondria $(33 \pm 5 \%, p<0.01)$. After blue LED light irradiation, $10 \mu \mathrm{M}$ A2E-laden cells exhibited mostly mitochondrial fragmentation, supporting the fact that, under these conditions, cells were more prone to die (Fig. 4e). An increased mitochondrial fission was also observed for $25 \mu \mathrm{M}$ A2E-laden cells with $(45 \pm 6 \%)$ and without light exposure $(31 \pm 8 \%)$ $(p<0.01)$ (Fig. 5b). Western blot analysis of mitochondrial shaping protein OPA1 and DRP1 levels support these findings (Fig. 5c).

OMA1 (overlapping activity with m-AAA protease) is a mitochondrial dysfunction sensor which is processed and activated against stress stimuli (e.g. mitochondrial membrane depolarization, apoptosis). Under these conditions, it has been demonstrated that OMA1 (40 kDa) is selfcleaved to generate an activated peptide (S-OMA1, $34 \mathrm{kDa}$ ). S-OMA1 activation results in the processing of OPA1, mitochondrial fragmentation, fusion inhibition and ultimately cell death (McBride and Soubannier 2010; Zhang et al. 2014; McVicar and Langer 2016). In our model, control cells exhibited a $\sim 40 \mathrm{kDa}$ band, the inactive OMA1 form. A2E per se or together with blue light induced the OMA1 self-cleavage revealed by the appearance of a $\sim 34 \mathrm{kDa}$ band. This effect was dependent on both light exposure and the A2E concentration.

\section{Discussion}

Although light is essential to vision, blue light exposure is a major environmental risk factor for AMD (Hunter et al. 2012). With the advent of LED-based technologies, there is an increasing concern about the so-called blue light hazard and its impact on the retina (Hunter et al. 2012; Kuse et al. 2014:; Gao et al. 2016; Jaadane et al. 2015, 2017). Despite the effect of low intensity blue LED light display devices on retinal damage has been examined (Marie et al. 2018; Moon et al. 2017) as far as we know the consequence of short exposure times on RPE integrity has not been addressed. Moreover, despite of the relevant role of mitochondrial injury in RPE damage, there are no reports focused on investigating the impact of blue light on mitochondrial dynamics.

In the present study, we designed a useful light device to employ in the $\mathrm{CO}_{2}$ incubator and evaluate the effects of light exposure on cellular features (Fig. 1a). This LED-based light source emitted at $4.43 \mathrm{~mW} / \mathrm{cm}^{2}, 445 \pm 18 \mathrm{~nm}$ blue light. The irradiance employed is in the intensity range of sunlight reaching the retina by taking into account the eye media transmittance (Arnault et al. 2013). Previous reports have demonstrated that $425-475 \mathrm{~nm}$ blue light caused damage to RPE, retinal ganglion cells and other epithelia (Roehlecke et al. 2009; Arnault et al. 2013; Lin et al. 2017 and references cited). Particularly, RPE cells were described as susceptible to high energy visible light wavelengths (Sparrow et al. 2002, 2003). Our results showed that 1-30 min exposure to blue LED light causes a time-dependent decrease in cell viability in ARPE-19 cells (Fig. 1b, c). Roehlecke et al. (2009) reported a metabolic activity decrease after irradiation for either 3 or $24 \mathrm{~h}$ with blue LED light $(405 \mathrm{~nm})$ at an output power of $1 \mathrm{~mW} / \mathrm{cm}^{2}$ and after $24 \mathrm{~h}$ irradiation at $0.3 \mathrm{~mW} / \mathrm{cm}^{2}$. Recently, Gea et al. (2018) also showed a timedependent cytotoxic effect in ARPE-19 cells after cold LED light exposure. However, considering the differences in light sources, irradiances and/or wavelength and exposure times employed, comparisons are quite complex.

Mitochondrial ROS production has been suggested as a major contributor to the cellular damage that underlies 
A

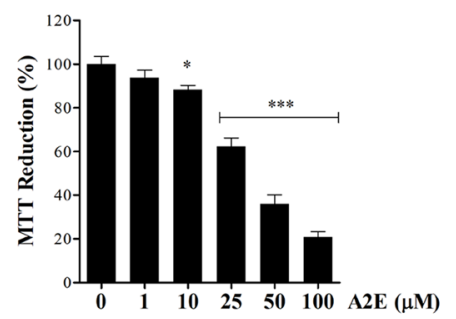

C

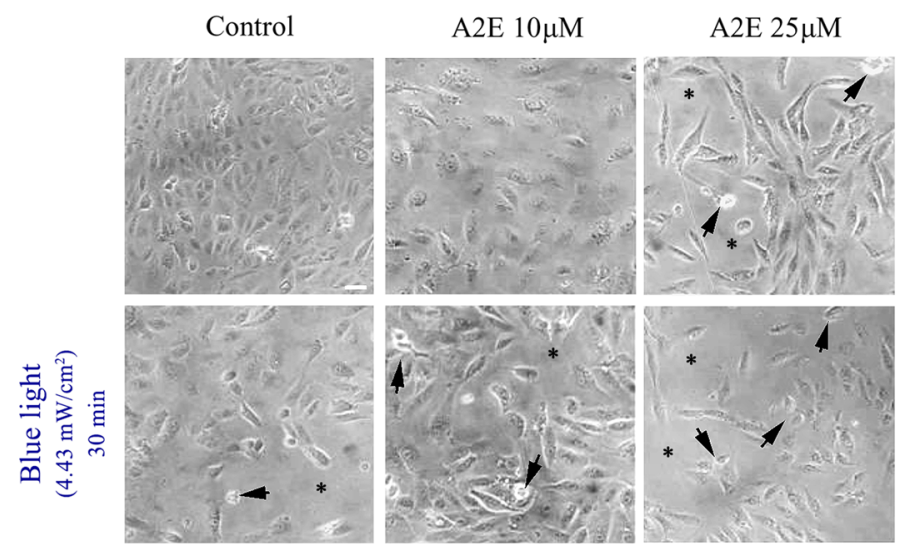

$\mathbf{E}$
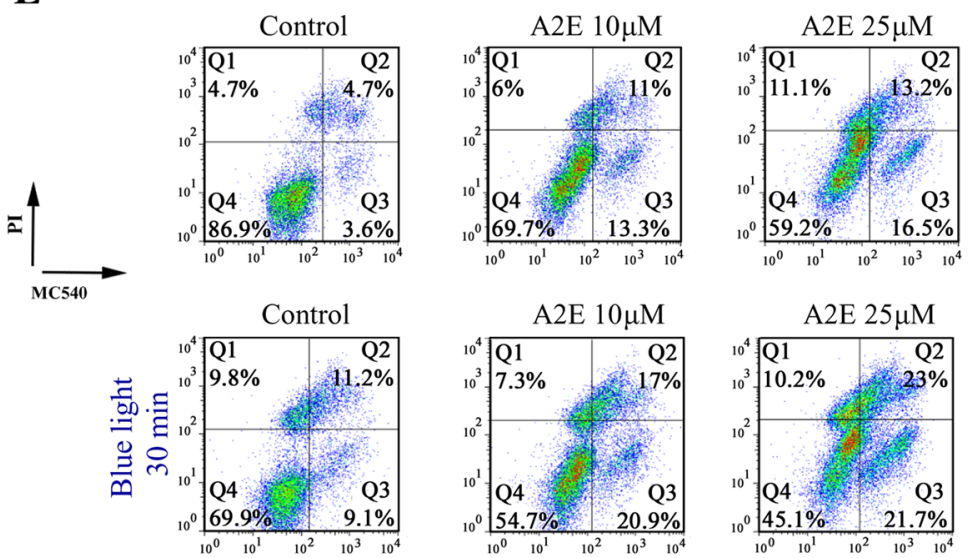

B

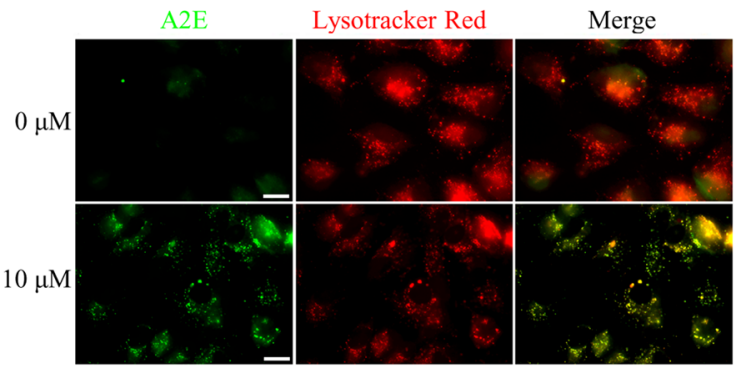

D
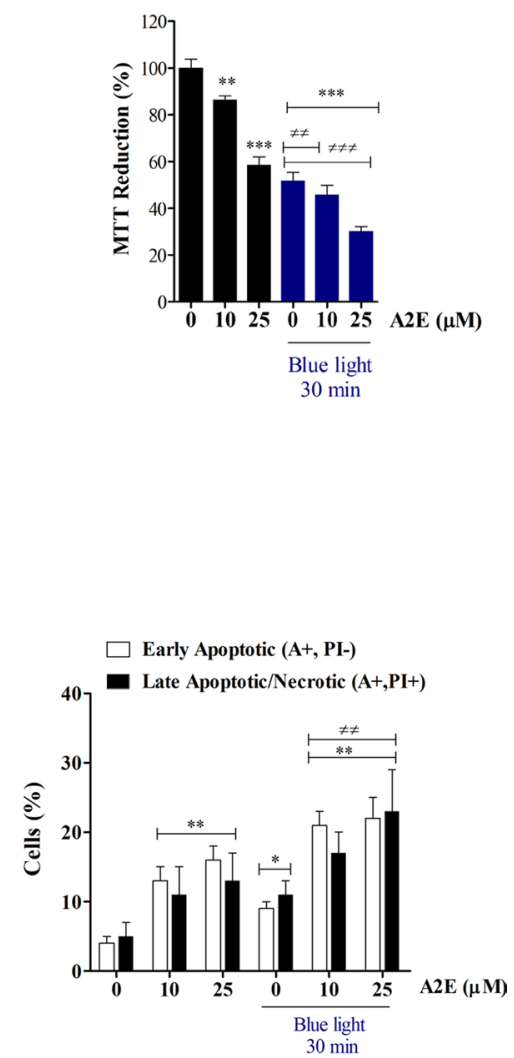

F

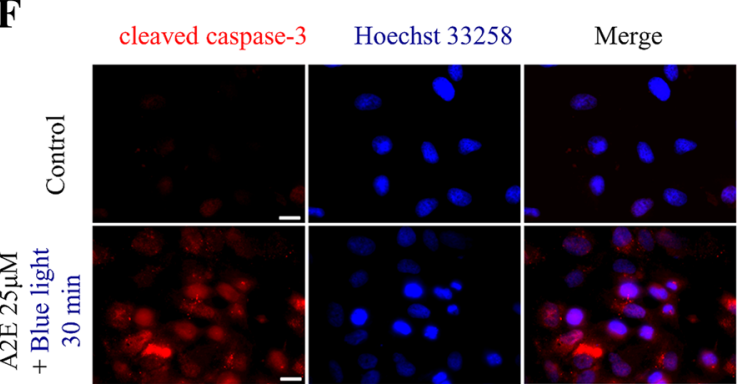

disease processes, especially age-related disorders. $\mathrm{O}_{2}{ }^{-}$is the proximal mitochondrial ROS and is highly unstable, being rapidly dismutated to $\mathrm{H}_{2} \mathrm{O}_{2}$ by Mn-SOD (Brand et al. 2004). In our model, we detected an important increase in mitochondrial $\mathrm{O}_{2}{ }^{-}$generation after 1-30 min of blue light exposure decreasing to the control levels after $60 \mathrm{~min}$ illumination (Fig. 2a-c). This decrease in $\mathrm{O}_{2}{ }^{-}$- generation could be explained by the subsequent formation of ROS other than 
4Fig. 4 A2E induces apoptosis in ARPE-19 cells. a Cell viability as a function of A2E concentration $(1-100 \mu \mathrm{M})$ was determined by MTT Assay. Data are presented as mean \pm SEM. $* p<0.05$, $* * * p<0.001$ vs. control (ANOVA, Newman-Keuls post-hoc test). b Colocalization between A2E (green) and acidic vesicles (AVOs) stained with Lysotracker Red DND-99. Control cells were incubated with DMSO $(0.01 \%)$. A2E ( $\left.\lambda_{\mathrm{ex}}: 488 \mathrm{~nm}, \lambda_{\mathrm{em}}: 510-530 \mathrm{~nm}\right)$, Lysotracker Red DND-99 ( $\left.\lambda_{\mathrm{ex}}: 543 \mathrm{~nm}, \lambda_{\mathrm{em}}: 585-605 \mathrm{~nm}\right)$. Scale bar: $10 \mu \mathrm{m}$. c Phasecontrast microscopy. Arrows indicated rounded and shrunken cells. d $\mathrm{A} 2 \mathrm{E}$ and blue light combined effect on cell viability assessed by MTT assay. ${ }^{* *} p<0.01,{ }^{* * *} p<0.001,{ }^{\neq} p<0.01,{ }^{\neq \neq} p<0.001$ vs. the corresponding control. e Left: apoptosis was analyzed with MC540/PI staining by flow cytometry. Right: bar graph quantifying the percentage of early apoptotic and late apoptotic/necrotic cells. f Cells were immunolabeled with specific anti-cleaved caspase- 3 antibody (red) and nuclei were stained with Hoechst 33258 (blue). Representative fluorescence images of each treatment are shown. Scale bar: $15 \mu \mathrm{m}$. (Color figure online)

$\mathrm{O}_{2}{ }^{-}$. In accordance with this proposal, total ROS production was elevated for all of the time points measured (Fig. 2b). Even so, other oxidative chain reactions involving ROS may be still occurring.

We next focused on the mechanism of blue light exposure-induced cell death by evaluating two apoptotic events: phosphatidylserine exposure and caspase- 3 activation (Galluzzi et al. 2018). We detected an increase in both early and late apoptotic/necrotic populations (Fig. 3b) accompanied by an increase in pro-caspase-3 levels (Fig. 3a). Several studies have previously revealed the contribution of apoptosis to the pathogenesis of retinal cell death in models of retinitis pigmentosa, AMD, glaucoma, retinal detachment, diabetic retinopathy and pathologic myopia (Wu et al. 2002). Regarding to light exposure, the occurrence of apoptosis with caspase-3 activation in RPE cells exposed to blue light has been reported (Sparrow and Cai 2001; Wu et al. 2002; Arnault et al. 2013; Chamorro et al. 2013; Lin et al. 2017). Besides, caspase-independent apoptosis or necroptosis was demonstrated after irradiation with white light (Chahory et al. 2010; Jaadane et al. 2015). In our model, the occurrence of this kind of cell death should not be discarded.

Mitochondria are highly dynamic organelles that can fuse and divide during cell life. Their morphologies are controlled by a tight balance between two antagonistic events: fusion and fission (McBride and Scorrano 2013). ARPE-19 cells exhibited elongated, thread-like mitochondria homogeneously distributed throughout the cytoplasm (Fig. 3b) as previously described (Marie et al. 2018). However, light exposure induced mitochondrial fragmentation, which was evidenced by the formation of smaller punctuated mitochondria. These results differ from those obtained by Roehlecke et al. (2009) who reported that blue LED light $(0.3 \mathrm{~mW} /$ $\mathrm{cm}^{2}$ and $1 \mathrm{~mW} / \mathrm{cm}^{2}, 72 \mathrm{~h}$ ) leads to the formation of giant elongated mitochondria, suggesting that the response against blue LED light strongly depends on the irradiation conditions. To gain further insight into mitochondrial dynamics, we focused on the two crucial mitochondria-shaping proteins OPA1 and DRP1. OPA1 is required for mitochondrial membrane fusion, while DRP1 is considered the master regulator of mitochondrial fission (McBride and Scorrano 2013). Blue LED light decreased OPA1 levels and increased DRP1 expression (Fig. 3d). These findings indicate that blue-LED light induces an imbalance in the fusion-fission equilibrium in ARPE-19 cells.

Lipofuscin accumulation is one of the most characteristic features of aging observed in human RPE cells. It is a complex aggregate of fluorescent material which major component is A2E. Intracellular accumulation of lipofuscin enhances cellular sensitivity to light radiation providing a possible cellular mechanism for AMD (Marie et al. 2018). This cellular photosensitization is partly attributed to A2E. Thus, loading RPE cells with A2E has been frequently employed as a model of AMD. According to Sparrow et al. (1999), the levels of A2E accumulated in ARPE19 cells incubated with $10-25 \mu \mathrm{M}$ A2E are comparable to those present in RPE cells from human eyes. Considering these findings and our results of cell viability (Fig. 4a) we have chosen to conduct most of our research by employing these concentrations. We first corroborated if A2E synthesized as described by Parish et al. (1998) presented the properties already described (Sparrow et al. 1999; Sparrow and Cai 2001; Finnemann et al. 2002; Arnault et al. 2013; Lu et al. 2017; Marie et al. 2018). Particularly, A2E was tracked and localized in AVOs (Fig. 4b). The fluorophore per se presented a dose-dependent cytotoxicity in ARPE-19 cells (Fig. 4a) and exacerbated the blue LED light-induced apoptotic cell death (Fig. 4e, f). Finally, we demonstrated that $\mathrm{A} 2 \mathrm{E}$ was able to increase mitochondrial $\mathrm{O}_{2}{ }^{-}$levels in the dark while no additional ROS generation was observed under blue light exposure (Fig. 5a). Although it has been reported that $\mathrm{A} 2 \mathrm{E}$ is a photosensitizer compound that produces $\mathrm{O}_{2}{ }^{-}$(Ben-Shabat et al. 2002) and mediates blue lightinduced damage to retinal RPE (Nita and Grzybowski 2016), to our knowledge there are only two works describing the combined effect of A2E and blue light on ROS generation in vitro. Marie et al. (2018) reported that A2E $(20 \mu \mathrm{M})$ loaded RPE cells produce twofold higher levels of $\mathrm{O}_{2}{ }^{-}$than those without A2E, even when maintained in the dark (controls). Blue LED light exposure $(15 \mathrm{~h})$, increased $\mathrm{O}_{2}{ }^{--}$production at levels below of 1.5 -fold. In contrast, $\mathrm{H}_{2} \mathrm{O}_{2}$ production was dramatically augmented (tenfold). In another report, Moon et al. (2017) demonstrated a threefold increment in $\mathrm{H}_{2} \mathrm{O}_{2}$ production in A2E-loaded ARPE-19 cells employing a low energy $\left(40 \mu \mathrm{W} / \mathrm{cm}^{2}\right)$ blue light emitting device (organic LED) and $48 \mathrm{~h}$ exposure. However, these authors did not find a cytotoxic effect of A2E per se in the dark. Results from Marie et al. (2018) and Moon et al. (2017) demonstrated that blue light irradiation greatly increased A2E-induced ROS production, especially leading to $\mathrm{O}_{2}{ }^{--}$dismutation. 
$\mathbf{A}$

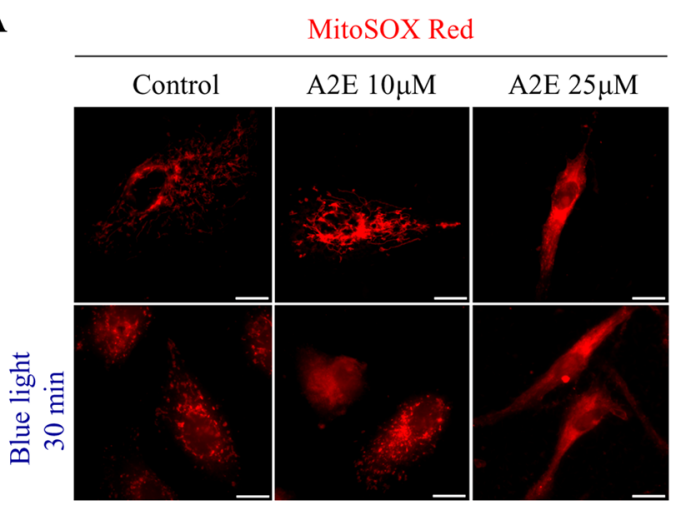

\section{B}
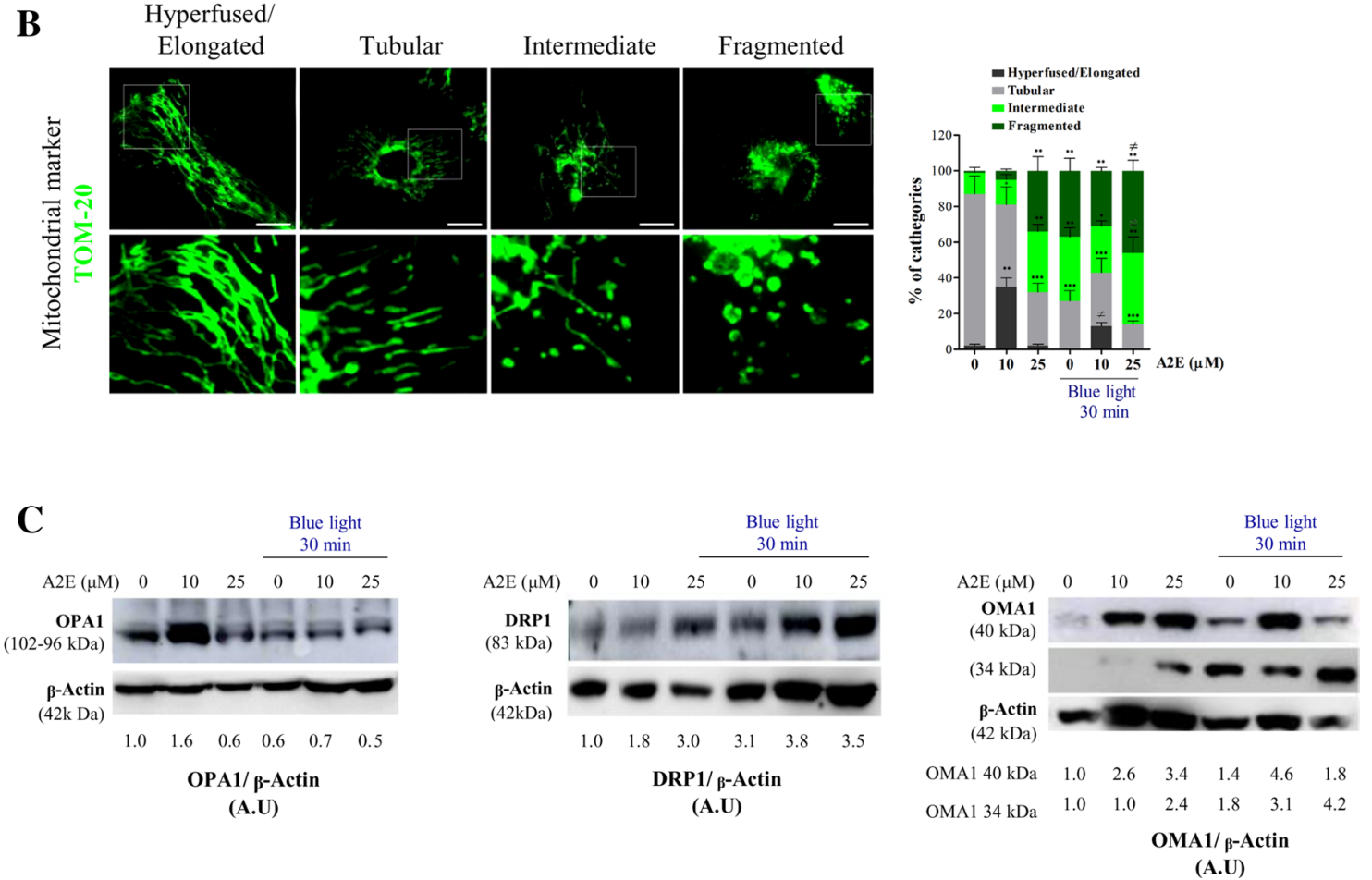

Fig. 5 Mitochondrial dynamics deregulation in A2E-loaded ARPE19 cells exposed to blue LED light. a Mitochondrial $\mathrm{O}_{2}{ }^{--}$generation was evaluated by fluorescence microscopy employing MitoSOX Red. Scale bar: $10 \mu \mathrm{m}$. b Mitochondrial morphology analysis. Epifluorescence images of TOM-20 immunocytochemistry (Olympus IX71, $\lambda_{\mathrm{ex}}: 488 \mathrm{~nm}$ ). Scale bar: $10 \mu \mathrm{m}$. Cells were categorized into four mor-

This could be the explanation for the absence of additional $\mathrm{O}_{2}{ }^{\cdot-}$ generation by blue light irradiation in ARPE- 19 cells loaded with $\mathrm{A} 2 \mathrm{E}$ in our model. Considering that $\mathrm{O}_{2}{ }^{-}$is the most relevant mitochondrial ROS, the non-occurrence of additional $\mathrm{O}_{2}{ }^{--}$levels but increased cell death suggests that (1) $\mathrm{O}_{2}{ }^{-}$is not the main player in the execution of cell death and/or (2) additional signaling pathways other than ROSmediated signaling pathway are involved in the blue lightmediated cell death in ARPE-19 cells as has been suggested
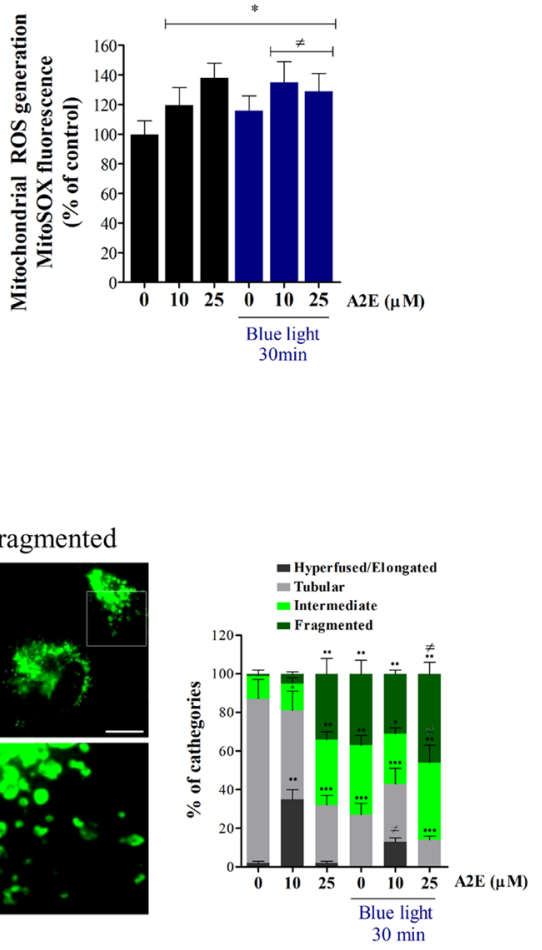

(A.U) phologies (hyperfused, tubular, intermediate and fragmented) and 200 cells/sample were counted. $\mathbf{c}$ Western blot analysis of mitochondrial fusion (OPA1) and fission (DRP1, OMA1) proteins. $\beta$-Actin was used for loading control. $* p<0.05, * * p<0.01, * * * p<0.001$ vs. control. ${ }^{f} p<0.05$ vs. the corresponding control. $A U$ arbitrary units

by Moon et al. (2017). Furthermore, findings described show that the response to A2E and light exposure is highly dependent on the experimental conditions (i.e. irradiation time and intensity).

Mitochondrial dysfunction has been implicated in the pathophysiology of several age-related diseases including AMD. More than 10 years ago, Feher et al. (2006) revealed a decrease in both the number and area of mitochondria, as well as a loss of cristae in human RPE from AMD patients. 
This was the initial finding that revealed the possible role of the mitochondrial dysfunction in AMD. Considering that changes in mitochondrial morphologic parameters are relevant for mitochondrial dynamics, we explored the effect of A2E and blue light exposure on mitochondrial dynamics. As far as we know there are no research focused in this issue.

Interestingly, $10 \mu \mathrm{M}$ A2E led to an increase in the percentage of ARPE-19 population with hyperfused/elongated mitochondria (Fig. 5b). It has been suggested that elongated mitochondria provide a stress-resolving cellular mechanism, as hyperfused mitochondria are spared from mitophagy (Gomes et al. 2011; Shutt and McBride 2013). However, a sustained hyperfusion increases the susceptibility to an additional stress as is the case of blue light exposure in A2E-loaded cells. On the other hand, $25 \mu \mathrm{M}$ A2E-laden cells under both dark and light conditions exhibited a fragmented mitochondrial network. This is probably due to the accumulated damage which could ultimately trigger apoptotic cell death. Hence, our findings propose that RPE cells seem to be especially sensitive to mitochondrial fusion/fission deregulation. In accordance with these morphological observations we detected changes in the expression levels of mitochondria-shaping proteins levels (OPA1, DPR1 and OMA1). In fact, light exposure of A2E-loaded cells contributes to decrease OPA1 and increase DRP1 and $34 \mathrm{kDa}$ OMA1 levels leading to mitochondrial fission (Fig. 5).

In summary, the present work clarifies the cellular and molecular mechanisms underlying phototoxicity in ARPE19 cells under short illumination periods and demonstrates for the first time that mitochondrial dynamics plays a role in blue LED light-induced damage in both unloaded and A2E-loaded cells. A deep comprehension of the underlying mitochondrial adaptation mechanisms against different levels of stress and how to modulate mitochondria-shaping proteins would enable to design novel strategies for AMD treatment and prevention.

Acknowledgements This work was supported by grants from the Consejo Nacional de Investigaciones Científicas y Técnicas (CONICET PIP 0771, PIP 0653) and University of Buenos Aires (UBACYT 20020130100212BA, 20020130200271BA and 20020170100755BA). J.M.B, R.M.G., S.P.A., J.H.M. are supported by a CONICET scholarship. A.A., G.G.L., A.B., H.E.G. and M.L.K. are researcher members at CONICET.

\section{Compliance with ethical standards}

Conflict of interest The authors declare no conflict of interest.

\section{References}

Alaimo A, Gorojod RM, Kotler ML (2011) The extrinsic and intrinsic apoptotic pathways are involved in manganese toxicity in rat astrocytoma C6 cells. Neurochem Int 59:297-308
Alaimo A, Gorojod RM, Miglietta EA, Villarreal A, Ramos AJ, Kotler ML (2013) Manganese induces mitochondrial dynamics impairment and apoptotic cell death: a study in human Gli36 cells. Neurosci Lett 554:76-81

Alaimo A, Gorojod RM, Beauquis J, Muñoz MJ, Saravia F, Kotler ML (2014) Deregulation of mitochondria-shaping proteins Opa-1 and Drp-1 in manganese-induced apoptosis. PLoS One 9:e91848

Ao J, Wood JP, Chidlow G, Gillies MC, Casson RJ (2018) Retinal pigment epithelium in the pathogenesis of age-related macular degeneration and photobiomodulation as a potential therapy? Clin Exp Ophthalmol 46:670-686

Arnault E, Barrau C, Nanteau C, Gondouin P, Bigot K, Viénot F, Gutman E, Fontaine V, Villette T, Cohen-Tannoudji D, Sahel JA, Picaud S (2013) Phototoxic action spectrum on a retinal pigment epithelium model of age-related macular degeneration exposed to sunlight normalized conditions. PLoS One 8:e71398

Barot M, Gokulgandhi MR, Mitra AK (2011) Mitochondrial dysfunction in retinal diseases. Curr Eye Res 36:1069-1077

Ben-Shabat S, Itagaki Y, Jockusch S, Sparrow JR, Turro NJ, Nakanishi $\mathrm{K}$ (2002) Formation of a nonaoxirane from A2E, a lipofuscin fluorophore related to macular degeneration, and evidence of singlet oxygen involvement. Angew Chem Int Ed Engl 41:814-817

Berman K, Brodaty H (2006) Psychosocial effects of age-related macular degeneration. Int Psychogeriatr 18:415-428

Blasiak J, Piechota M, Pawlowska E, Szatkowska M, Sikora E, Kaarniranta K. Cellular senescence in age-related macular degeneration: can autophagy and DNA damage response play a role? Oxid Med Cell Longev 2017: 5293258

Bradford MM (1976) A rapid and sensitive method for the quantitation of microgram quantities of protein utilizing the principle of protein-dye binding. Anal Biochem 72:248-254

Brand MD, Affourtit C, Esteves TC, Green K, Lambert AJ, Miwa S, Pakay JL, Parker N (2004) Mitochondrial superoxide: production, biological effects, and activation of uncoupling proteins. Free Radic Biol Med 37:755-767

Brandstetter C, Mohr LK, Latz E, Holz FG, Krohne TU (2015) Light induces NLRP3 inflammasome activation in retinal pigment epithelial cells via lipofuscin-mediated photooxidative damage. J Mol Med (Berl) 93:905-916

Chahory S, Keller N, Martin E, Omri B, Crisanti P, Torriglia A (2010) Light induced retinal degeneration activates a caspase-independent pathway involving cathepsin D. Neurochem Int 57:278-287

Chamorro E, Bonnin-Arias C, Pérez-Carrasco MJ, Muñoz de Luna J, Vázquez D, Sánchez-Ramos C (2013) Effects of light-emitting diode radiations on human retinal pigment epithelial cells in vitro. Photochem Photobiol 89:468-473

Chauhan A, Vera J, Wolkenhauer O (2014) The systems biology of mitochondrial fission and fusion and implications for disease and aging. Biogerontology 15:1-12

Contín MA, Arietti MM, Benedetto MM, Bussi C, Guido ME (2013) Photoreceptor damage induced by low- intensity light: model of retinal degeneration in mammals. Mol Vis 19:1614-1625

Dunn KC, Aotaki-Keen AE, Putkey FR, Hjelmeland LM (1996) ARPE19 , a human retinal pigment epithelial cell line with differentiated properties. Exp Eye Res 62:155-169

Feher J, Kovacs I, Artico M, Cavallotti C, Papale A, Balacco Gabrieli C (2006) Mitochondrial alterations of retinal pigment epithelium in age-related macular degeneration. Neurobiol Aging 27:983-989

Fernández-Robredo P, Sancho A, Johnen S, Recalde S, Gama N, Thumann G, Groll J, García-Layana A (2014) Current treatment limitations in age-related macular degeneration and future approaches based on cell therapy and tissue engineering. J Ophthalmol 2014:510285

Finnemann SC, Leung LW, Rodriguez-Boulan E (2002) The lipofuscin component A2E selectively inhibits phagolysosomal degradation 
of photoreceptor phospholipid by the retinal pigment epithelium. Proc Natl Acad Sci USA 99:3842-3847

Fritsche LG, Fariss RN, Stambolian D, Abecasis GR, Curcio CA, Swaroop A (2014) Age-related macular degeneration: genetics and biology coming together. Annu Rev Genomics Hum Genet 15:151-171

Galluzzi L, Vitale I, Aaronson SA, Abrams JM, Adam D, Agostinis P et al (2018) Molecular mechanisms of cell death: recommendations of the Nomenclature Committee on Cell Death 2018. Cell Death Differ 25:486-541

Gao ML, Deng WL, Huang N, Wang YY, Lei XL, Xu ZQ, Hu DN, Cai JQ, Lu F, Jin ZB (2016) Upregulation of GADD45 $\alpha$ in light-damaged retinal pigment epithelial cells. Cell Death Discov 2:16013

Gea M, Schilirò T, Iacomussi P, Degan R, Bonetta S, Gilli G (2018) Cytotoxicity and genotoxicity of light emitted by incandescent, halogen, and LED bulbs on ARPE-19 and BEAS-2B cell lines. J Toxicol Environ Health A 81:998-1014

Godley BF, Shamsi FA, Liang FQ, Jarrett SG, Davies S, Boulton $\mathrm{M}$ (2005) Blue light induces mitochondrial DNA damage and free radical production in epithelial cells. J Biol Chem 280:21061-21066

Gomes LC, Di Benedetto G, Scorrano L (2011) During autophagy mitochondria elongate, are spared from degradation and sustain cell viability. Nat Cell Biol 13:589-598

Gorojod RM, Alaimo A, Porte Alcon S, Pomilio C, Saravia F, Kotler ML (2015) The autophagic-lysosomal pathway determines the fate of glial cells under manganese-induced oxidative stress conditions. Free Radic Biol Med 87:237-251

Gorojod RM, Alaimo A, Porte Alcon S, Martinez JH, Cortina ME, Vazquez ES, Kotler ML (2018) Heme oxygenase-1 protects astroglia against manganese-induced oxidative injury by regulating mitochondrial quality control. Toxicol Lett 295:357-368

Huang C, Zhang P, Wang W, Xu Y, Wang M, Chen X, Dong X (2014) Long-term blue light exposure induces RGC-5 cell death in vitro: involvement of mitochondria-dependent apoptosis, oxidative stress, and MAPK signaling pathways. Apoptosis 19:922-932

Hunter JJ, Morgan JI, Merigan WH, Sliney DH, Sparrow JR, Williams DR (2012) The susceptibility of the retina to photochemical damage from visible light. Prog Retin Eye Res 31:28-42

Jaadane I, Boulenguez P, Chahory S, Carré S, Savoldelli M, Jonet L, Behar-Cohen F, Martinsons C, Torriglia A (2015) Retinal damage induced by commercial light emitting diodes (LEDs). Free Radic Biol Med 84:373-384

Jaadane I, Villalpando Rodriguez GE, Boulenguez P, Chahory S, Carré S, Savoldelli M, Jonet L, Behar-Cohen F, Martinsons C, Torriglia A (2017) Effects of white light-emitting diode (LED) exposure on retinal pigment epithelium in vivo. J Cell Mol Med 21:3453-3466

Kaarniranta K, Sinha D, Blasiak J, Kauppinen A, Veréb Z, Salminen A, Boulton ME, Petrovski G (2013) Autophagy and heterophagy dysregulation leads to retinal pigment epithelium dysfunction and development of age-related macular degeneration. Autophagy 9:973-984

Karunadharma PP, Nordgaard CL, Olsen TW, Ferrington DA (2010) Mitochondrial DNA damage as a potential mechanism for agerelated macular degeneration. Investig Ophthalmol Vis Sci 51:5470-5479

Kauppinen A, Paterno JJ, Blasiak J, Salminen A, Kaarniranta K (2016) Inflammation and its role in age-related macular degeneration. Cell Mol Life Sci 73:1765-1786

Kotiadis VN, Duchen MR, Osellame LD (2014) Mitochondrial quality control and communications with the nucleus are important in maintaining mitochondrial function and cell health. Biochim Biophys Acta 1840:1254-1265

Kuse Y, Ogawa K, Tsuruma K, Shimazawa M, Hara H (2014) Damage of photoreceptor-derived cells in culture induced by light emitting diode-derived blue light. Sci Rep 4:5223
Laakko T, King L, Fraker P (2002) Versatility of merocyanine 540 for the flow cytometric detection of apoptosis in human and murine cells. J Immunol Methods 261:129-139

Lambert NG, ElShelmani H, Singh MK, Mansergh FC, Wride MA, Padilla M, Keegan D, Hogg RE, Ambati BK (2016) Risk factors and biomarkers of age-related macular degeneration. Prog Retin Eye Res 54:64-102

Liesa M, Palacín M, Zorzano A (2009) Mitochondrial dynamics in mammalian health and disease. Physiol Rev 89:799-845

Lin $\mathrm{CH}$, Wu MR, Li CH, Cheng HW, Huang SH, Tsai CH, Lin FL, Ho JD, Kang JJ, Hsiao G, Cheng YW (2017) Editor's highlight: periodic exposure to smartphone-mimic low-luminance blue light induces retina damage through Bcl-2/BAX-dependent apoptosis. Toxicol Sci 157:196-210

Lionaki E, Markaki M, Palikaras K, Tavernarakis N (2015) Mitochondria, autophagy and age-associated neurodegenerative diseases: new insights into a complex interplay. Biochim Biophys Acta 1847:1412-1423

Lu B, Zhang P, Zhou M, Wang W, Gu Q, Feng J, Luo X, Sun X, Wang F, Sun X (2017) Involvement of XBP1s in blue lightinduced A2E-containing retinal pigment epithelium cell death. Ophthalmic Res 57:252-262

Marie M, Bigot K, Angebault C, Barrau C, Gondouin P, Pagan D, Fouquet S, Villette T, Sahel JA, Lenaers G, Picaud S (2018) Light action spectrum on oxidative stress and mitochondrial damage in A2E-loaded retinal pigment epithelium cells. Cell Death Dis 9:287

McBride H, Scorrano L (2013) Mitochondrial dynamics and physiology. Biochim Biophys Acta 1833:148-149

McBride H, Soubannier V (2010) Mitochondrial function: OMA1 and OPA1, the grandmasters of mitochondrial health. Curr Biol 20:R274-R276

McVicar T, Langer T (2016) OPA1 processing in cell death and disease - the long and short of it. J Cell Sci 129:2297-2306

Moon J, Yun J, Yoon YD, Park SI, Seo YJ, Park WS, Chu HY, Park KH, Lee MY, Lee CW, Oh SJ, Kwak YS, Jang YP, Kang JS (2017) Blue light effect on retinal pigment epithelial cells by display devices. Integr Biol (Camb) 9:436-443

Mosmann T (1983) Rapid colorimetric assay for cellular growth and survival: application to proliferation and cytotoxicity assays. J Immunol Methods 65:55-63

Nita M, Grzybowski A (2016) The role of the reactive oxygen species and oxidative stress in the pathomechanism of the agerelated ocular diseases and other pathologies of the anterior and posterior eye segments in adults. Oxid Med Cell Longev 2016:3164734

Parish CA, Hashimoto M, Nakanishi K, Dillon J, Sparrow J (1998) Isolation and one-step preparation of $\mathrm{A} 2 \mathrm{E}$ and iso-A2E, fluorophores from human retinal pigment epithelium. Proc Natl Acad Sci USA 95:14609-14613

Porte Alcon S, Gorojod RM, Kotler ML (2018) Regulated necrosis orchestrates microglial cell death in manganese-induced toxicity. Neuroscience 393:206-225

Robinson KM, Janes MS, Beckman JS (2008) The selective detection of mitochondrial superoxide by live cell imaging. Nat Protoc 3:941-947

Roehlecke C, Schaller A, Knels L, Funk RH (2009) The influence of sublethal blue light exposure on human RPE cells. Mol Vis 15:1929-1938

Shutt TE, McBride HM (2013) Staying cool in difficult times: mitochondrial dynamics, quality control and the stress response. Biochim Biophys Acta 1833:417-424

Sparrow JR, Cai B (2001) Blue light-induced apoptosis of A2Econtaining RPE: involvement of caspase- 3 and protection by Bcl-2. Investig Ophthalmol Vis Sci 42:1356-1362 
Sparrow JR, Parish CA, Hashimoto M, Nakanishi K (1999) A2E, a lipofuscin fluorophore, in human retinal pigmented epithelial cells in culture. Investig Ophthalmol Vis Sci 40:2988-2995

Sparrow JR, Zhou J, Ben-Shabat S, Vollmer H, Itagaki Y, Nakanishi K (2002) Involvement of oxidative mechanisms in blue-lightinduced damage to A2E-laden RPE. Investig Ophthalmol Vis Sci 43:1222-1227

Sparrow JR, Fishkin N, Zhou J, Cai B, Jang YP, Krane S, Itagaki Y, Nakanishi K (2003) A2E, a byproduct of the visual cycle. Vis Res 43:2983-2989

Stotland A, Gottlieb RA (2015) Mitochondrial quality control: easy come, easy go. Biochim Biophys Acta 1853:2802-2811

Suen DF, Norris KL, Youle RJ (2008) Mitochondrial dynamics and apoptosis. Genes Dev 22:1577-1590

Sui GY, Liu GC, Liu GY, Gao YY, Deng Y, Wang WY, Tong SH, Wang L (2013) Is sunlight exposure a risk factor for age-related macular degeneration? A systematic review and meta-analysis. $\mathrm{Br}$ J Ophthalmol 97:389-394

Suter M, Remé C, Grimm C, Wenzel A, Jäättela M, Esser P, Kociok N, Leist M, Richter C (2000) Age-related macular degeneration. The lipofusion component $N$-retinyl- $N$-retinylidene ethanolamine detaches proapoptotic proteins from mitochondria and induces apoptosis in mammalian retinal pigment epithelial cells. J Biol Chem 275:39625-39630

Torriglia A, Jaadane I, Lebon C (2016) Mechanisms of cell death in neurodegenerative and retinal diseases: common pathway? Curr Opin Neurol 29:55-60

Tosini G, Ferguson I, Tsubota K (2016) Effects of blue light on the circadian system and eye physiology. Mol Vis 22:61-72

Vives-Bauza C, Anand M, Shiraz AK, Magrane J, Gao J, Vollmer-Snarr HR, Manfredi G, Finnemann SC (2008) The age lipid A2E and mitochondrial dysfunction synergistically impair phagocytosis by retinal pigment epithelial cells. J Biol Chem 28:24770-24780

Wihlmark U, Wrigstad A, Roberg K, Nilsson SE, Brunk UT (1997) Lipofuscin accumulation in cultured retinal pigment epithelial cells causes enhanced sensitivity to blue light irradiation. Free Radic Biol Med 22:1229-1234

Winkler BS, Boulton ME, Gottsch JD, Sternberg P (1999) Oxidative damage and age-related macular degeneration. Mol Vis 5:32

Wojtala A, Bonora M, Malinska D, Pinton P, Duszynski J, Wieckowski MR (2014) Methods to monitor ROS production by fluorescence microscopy and fluorometry. Methods Enzymol 542:243-262

Wolf G (2003) Lipofuscin and macular degeneration. Nutr Rev 61:342-346

Wong WL, Su X, Li X, Cheung CM, Klein R, Cheng CY, Wong TY (2014) Global prevalence of age-related macular degeneration and disease burden projection for 2020 and 2040: a systematic review and meta-analysis. Lancet Glob Health 2:e106-e116

Wu J, Gorman A, Zhou X, Sandra C, Chen E (2002) Involvement of caspase-3 in photoreceptor cell apoptosis induced by in vivo blue light exposure. Investig Ophthalmol Vis Sci 43:3349-3354

Youle RJ, Karbowski M (2005) Mitochondrial fission in apoptosis. Nat Rev Mol Cell Biol 6:657-663

Zhang K, Li H, Song Z (2014) Membrane depolarization activates the mitochondrial protease OMA1 by stimulating self-cleavage. EMBO Rep 15:576-585

Publisher's Note Springer Nature remains neutral with regard to jurisdictional claims in published maps and institutional affiliations.

\section{Affiliations}

\section{Agustina Alaimo ${ }^{1}$ Guadalupe García Liñares ${ }^{2}$ Juan Marco Bujjamer ${ }^{3} \cdot$ Roxana Mayra Gorojod $^{1}$. Soledad Porte Alcon ${ }^{1} \cdot$ Jimena Hebe Martínez ${ }^{1}$ - Alicia Baldessari ${ }^{2} \cdot$ Hernán Edgardo Grecco $^{3} \cdot$ Mónica Lidia Kotler $^{1}$ (D)}

Agustina Alaimo

aalaimo@qb.fcen.uba.ar; agusalaimo@gmail.com

Guadalupe García Liñares

linares@qo.fcen.uba.ar

Juan Marco Bujjamer

jubujjamer@df.uba.ar

Roxana Mayra Gorojod

rgorojod@qb.fcen.uba.ar

Soledad Porte Alcon

sportealcon@qb.fcen.uba.ar

Jimena Hebe Martínez

jhebemartinez@gmail.com

Alicia Baldessari

alib@qo.fcen.uba.ar

Hernán Edgardo Grecco

hgrecco@df.uba.ar
1 Departamento de Química Biológica, Facultad de Ciencias Exactas y Naturales, Instituto de Química Biológica Ciencias Exactas y Naturales (IQUIBICEN), CONICET-Universidad de Buenos Aires, Pabellón 2, Ciudad Universitaria, 1428 Buenos Aires, Argentina

2 Departamento de Química Orgánica, Facultad de Ciencias Exactas y Naturales, Unidad de Microanálisis y Métodos Físicos en Química Orgánica (UMYNFOR), CONICET-Universidad de Buenos Aires, Pabellón 2, Ciudad Universitaria, 1428 Buenos Aires, Argentina

3 Departamento de Física, Facultad de Ciencias Exactas y Naturales, Instituto de Física de Buenos Aires (IFIBA), CONICET-Universidad de Buenos, Pabellón 1, Ciudad Universitaria, 1428 Buenos Aires, Argentina 